Investigaciones Feministas

ISSN-e: 2171-6080

http://dx.doi.org/10.5209/INFE.54969

\title{
Disensos feministas
}

Daniela Alegría Fuentes

Alejandra Castillo, Palinodia, Santiago de Chile, 2016, 136 páginas, ISBN 978-956-8438-46-3

La autora señala, citando a la feminista chilena Julieta Kirkwood, que el feminismo insta a que las mujeres se introduzcan en el mundo como mujeres conscientes de su condición (Feminarios, 1987). No obstante, "es necesaria también una política de la disidencia. Afirmar y disentir a la vez" (p. 10). La profesora Castillo pretende mostrar en este libro el gesto disidente en un doble movimiento: $i$ ) como una reescritura crítica de la teoría política desde una perspectiva femenina, y ii) como un cuestionamiento a los planteamientos feministas que, creyendo salir del orden masculino-patriarcal, adoptan las éticas o políticas del cuidado (cfr. 13).

El libro se divide en cinco partes. En la primera sección se busca criticar la democracia liberal y proponer una democracia de participación más efectiva. No solo es preciso criticar el credo liberal democrático por ser "abstracto y patriarcal", sino que se deben buscar nuevas formas de identificación social y modos de representación política allende los marcos clásicos de representación "universalista" del individuo-ciudadano ( $c f r$. p. 32). En la última parte de esta sección Castillo cuestiona la introducción de la mujer en los gobiernos de Michelle Bachelet. La autora afirma que la visibilización de las mujeres en política en Chile se ha desarrollado a través de la implementación de "políticas del cuidado" (desarrollado también en La república masculina y la promesa igualitaria; 2005). Las políticas del cuidado traerán problemas al representar a las mujeres nuevamente en términos conservadores y tradicionales, reforzando el vínculo entre la mujer y el cuidado.

En la segunda sección se muestra cómo la mujer ha sido asociada a los términos de amor y cuidado para señalar, más tarde, que existen dos lecturas posibles de esta asociación: $i$ ) la lectura anti-feminista, y $i$ ) la lectura feminista. La primera lectura sitúa al cuidado como encarnando el típico rol femenino "de guardiana de las tradiciones y de reservorio moral de la comunidad" (p. 36). La segunda, en cambio, le otorga un diferente estatuto político y social. Esta corriente de análisis lleva por nombre "ética del cuidado" o "pensamiento maternalista". Rápidamente y sin mayor explicación, la autora pasa del ámbito ético del cuidado a sostener que este se vuelve otra forma de hacer política.

Para contextualizar la investigación en torno al cuidado la profesora Castillo recorre el célebre libro de Carol Gilligan In a Different Voice: Psychological Theory and Women's Development (1982) y ejemplifica a través de Sara Ruddick el que se pueda hablar de "política maternalista del cuidado". Las mujeres, en los trabajos anteriores a los de Gilligan, aparecen con un desarrollo moral deficiente en los estudios de psicología moral de, por ejemplo, Sigmund Freud, Jean Piaget y 
Lawrence Kohlberg. Los seis estadios del juicio moral de Kohlberg, que se basan por más de veinte años en el seguimiento a ochenta y cuatro niños varones, perpetúan la deficiencia moral femenina por no alcanzar el principio de imparcialidad del último estadio. De acuerdo con Kohlberg las mujeres se posicionan en el Nivel II y Estadio III mientras que los hombres pueden alcanzar el Nivel III y Estadio VI.

En la tercera sección, la profesora chilena señala que todavía valdría la pena revisar una vez más el debate entre liberales y comunitaristas (entre políticas o justicias abstractas y universalistas, o bien políticas o justicias concretas y particularistas). A lo largo de este capítulo se muestran las críticas feministas a la política moderna en torno a la lentitud con que han llegado a la vida de las mujeres la igualdad, la libertad y los derechos. Esta tardanza se debe a cierta estructura patriarcal que se reproduce desde la propia teoría política, ya sea en su versión liberal o en su versión republicana.

Al final del libro, en la sección cuarta y quinta, la autora conjuga la tradición anglosajona del cuidado con América Latina, señala que "a partir de los años noventa se empezará a transitar desde las éticas del cuidado hacia políticas del cuidado con una fuerte impronta maternalista (...) Se trata, en otras palabras, de establecer una ética de la responsabilidad y volver al cuidado un tema políticamente relevante" ( $\mathrm{p}$. 71-2). Castillo pone énfasis en las políticas de la presencia (i.e., políticas que buscan incentivar la participación de las mujeres en todos los ámbitos) adoptadas primera vez en Noruega para hablar del caso latinoamericano. Las mujeres demandan ser incorporadas al mundo de la política no solo por ser "mujeres", sino porque son sujetos de derechos, con iguales capacidades y méritos ( $c f r$. p. 84). El problema es que el cuidado es para la autora un síntoma del neoliberalismo y un síntoma también de una democracia elitista. Así, la autora busca poner en cuestión las políticas del cuidado. Las políticas llevadas a cabo por los gobiernos de la Concertación en Chile (ahora Nueva Mayoría) se han hecho en nombre de "políticas de género" pero, si es que podrían ser consideradas políticas feministas, el feminismo institucional chileno es "liberal" y de marco heteronormativo.

Destaco, pues, la relevancia del libro tanto por su contenido filosófico como por la conjunción del cuidado con la política latinoamericana, con énfasis en Chile y la figura de la presidenta Bachelet. Destaco, también, las críticas y propuestas que se encuentran en las dos últimas secciones en torno a la convocatoria de una asamblea constituyente. Si bien es cierto que se echan de menos algunas explicaciones (v.gr. por qué hablar de éticas del cuidado en plural, entre otras) y es posible encontrar algunas erratas, el libro reseñado es una importante contribución al desarrollo de las investigaciones feministas. 